\title{
Communication
}

\section{Tagging and Capturing of Lentiviral Vectors Using Short RNAs}

\author{
Martin Panigaj 1,2®, Michael P. Marino ${ }^{2}$ and Jakob Reiser ${ }^{2, *}$ \\ 1 Faculty of Science, Institute of Biology and Ecology, Pavol Jozef Safarik University in Kosice, \\ 04154 Kosice, Slovakia; martin.panigaj@gmail.com \\ 2 Center for Biologics Evaluation and Research, Division of Cellular and Gene Therapies, \\ U.S. Food and Drug Administration, Silver Spring, MD 20993, USA; Yorick73@cox.net \\ * Correspondence: Jakob.Reiser@fda.hhs.gov
}

Citation: Panigaj, M.; Marino, M.P.; Reiser, J. Tagging and Capturing of Lentiviral Vectors Using Short RNAs. Int. J. Mol. Sci. 2021, 22, 10263. https://doi.org/10.3390/ ijms221910263

Academic Editor: József Tőzsér

Received: 2 August 2021

Accepted: 19 September 2021

Published: 23 September 2021

Publisher's Note: MDPI stays neutral with regard to jurisdictional claims in published maps and institutional affiliations.

Copyright: (C) 2021 by the authors. Licensee MDPI, Basel, Switzerland. This article is an open access article distributed under the terms and conditions of the Creative Commons Attribution (CC BY) license (https:// creativecommons.org/licenses/by/ $4.0 /)$.

\begin{abstract}
Lentiviral (LV) vectors have emerged as powerful tools for transgene delivery ex vivo but in vivo gene therapy applications involving LV vectors have faced a number of challenges, including the low efficiency of transgene delivery, a lack of tissue specificity, immunogenicity to both the product encoded by the transgene and the vector, and the inactivation of the vector by the human complement cascade. To mitigate these issues, several engineering approaches, involving the covalent modification of vector particles or the incorporation of specific protein domains into the vector's envelope, have been tested. Short synthetic oligonucleotides, including aptamers bound to the surface of LV vectors, may provide a novel means with which to retarget LV vectors to specific cells and to shield these vectors from neutralization by sera. The purpose of this study was to develop strategies to tether nucleic acid sequences, including short RNA sequences, to LV vector particles in a specific and tight fashion. To bind short RNA sequences to LV vector particles, a bacteriophage lambda $N$ protein-derived RNA binding domain $(\lambda N)$, fused to the measles virus hemagglutinin protein, was used. The $\lambda \mathrm{N}$ protein bound RNA sequences bearing a boxB RNA hairpin. To test this approach, we used an RNA aptamer specific to the human epidermal growth factor receptor (EGFR), which was bound to LV vector particles via an RNA scaffold containing a boxB RNA motif. The results obtained confirmed that the EGFR-specific RNA aptamer bound to cells expressing EGFR and that the boxB containing the RNA scaffold was bound specifically to the $\lambda \mathrm{N}$ RNA binding domain attached to the vector. These results show that $L V$ vectors can be equipped with nucleic acid sequences to develop improved LV vectors for in vivo applications.
\end{abstract}

Keywords: lentiviral vectors; vector engineering; pseudotyping; vector targeting; nucleic acid aptamers

\section{Introduction}

Over the past two and a half decades, lentiviral (LV) vectors have emerged as powerful tools for transgene delivery [1]. LV vectors have been tested in numerous clinical trials involving ex vivo transduced cells, such as hematopoietic stem cells and mature $\mathrm{T}$ cells $[2,3]$. Four LV vector-based gene therapy products have received regulatory approval, including Kymriah (tisagenlecleucel) for the treatment of relapsed/refractory B cell acute lymphoblastic leukemia (B-ALL) [4], Zynteglo (betibeglogene autotemcel) for the treatment of transfusion-dependent beta-thalassemia [5], Breyanzi (lisocabtagene maraleucel) for the treatment of relapsed or refractory large B cell lymphoma (LBCL) [6] and Abecma (idecabtagene vicleucel) for the treatment of adult patients with relapsed or refractory multiple myeloma [7].

LV vectors are also applied directly in vivo for therapeutic purposes. A non-primate LV vector system based on equine infectious anemia virus (EIAV) has been investigated clinically to treat ocular disorders [8]. In another in vivo application, an HIV-1-based, integrationdeficient LV vector expressing the NY-ESO-1 cancer testis antigen targeted to dendritic cells was used to promote an immune response against NY-ESO-1-expressing tumors [9]. 
The design of LV vectors to allow the targeted transduction of specific cell types in vivo has been challenging and the efficacy of such vectors can be affected by neutralizing antibodies. Virus engineering approaches have been critical in helping to address some of these issues [10-12]. For example, a number of pseudotyping strategies aimed at broadening the tropism of $\mathrm{LV}$ vectors to transduce previously nonpermissive cells or to replace the vector's tropism in order to transduce specific target cells exclusively have been described [13]. Pseudotyped retroviral vector particles bear envelope glycoproteins derived from other enveloped viruses and acquire the tropism of the virus from which the glycoprotein was derived [12,14-16]. A versatile strategy for LV vector targeting involving engineered measles virus (MV) hemagglutinin $(\mathrm{H})$ and fusion $(\mathrm{F})$ glycoproteins has emerged $[12,17,18]$. Various protein ligands, including epidermal growth factor (EGF) [19], IL-13 [20], single-chain antibodies [21] and designed ankyrin repeat proteins (DARPins) [22] have been successfully displayed using MV H, allowing retargeted LV vector delivery.

Engineering strategies aimed at the enhancement of the purification of LV vectors have also been investigated. For example, Yu et al. [23] used a library screening approach to identify variants of the vesicular stomatitis virus $G$ protein (VSV-G) bearing hexahistidine tags, allowing the purification of LV vectors using Ni-nitrilotriacetic acid (NTA) affinity chromatography. Similarly, biotin has been displayed on the surface of LV vectors via the metabolic biotinylation of a low-affinity nerve growth factor receptor (LNGFR) domain incorporated on the vector's surface, allowing the capture of vector particles by immobilized streptavidin and elution, via the addition of biotin [24].

Surface modification approaches have also been used to dampen innate immune responses to LV vectors [25]. LV vectors pseudotyped with VSV-G have long been known to be sensitive to complement-mediated inactivation by human serum [26]. Recent work by Munis et al. has revealed that alternative LV vector pseudotypes involving heterologous vesiculovirus $\mathrm{G}$ glycoproteins may ultimately allow the circumvention of this issue [27]. Furthermore, the co-display of complement-regulatory proteins on LV particles, especially decay accelerating factor (DAF)/CD55, has been shown to confer a significant level of protection against complement attack [28].

Other approaches to the modification of the surface of $L V$ vectors have included direct covalent modification. Shielding of VSV-G-pseudotyped LV vectors by poly(ethylene) glycol (PEG) conjugation (PEGylation) was shown by Croyle et al. [29] to increase the resistance of these vectors to complement-mediated inactivation. An alternative approach to the shielding of VSV-G pseudotyped LV vectors, involving a thin polymer shell synthesized in situ onto the vector's envelope, was described by Liang et al. [30]. The shielded vector possessed enhanced stability in the presence of human serum, indicating protection of the vector by the polymer shell from human serum complement inactivation.

The goal of this study was to develop novel approaches to tether short RNA sequences to $\mathrm{LV}$ vector particles in a specific fashion, using RNA binding proteins. The bacteriophage $\lambda \mathrm{N}$ protein-boxB system [31] provided a promising solution to this problem. The $\lambda \mathrm{N}$ protein, fused to the MV H protein displayed on the LV vector particles, enabled the capture of vector particles by using magnetic beads via an RNA scaffold containing a boxB sequence, as well as the transduction of target cells.

\section{Results}

\subsection{Design of RNA Scaffolds Capable of Binding to a Bacteriophage Lambda N Protein}

To attach RNA sequences to LV vector particles, a 22 amino acid RNA binding domain $(\lambda \mathrm{N})$ derived from the bacteriophage lambda antitermination protein $\mathrm{N}[31,32]$ was used. The $\lambda \mathrm{N}$ protein has the capacity to bind to a 19 nucleotide RNA target sequence, referred to as the boxB RNA motif [31].

In our approach, the $\lambda \mathrm{N}$ domain bound to a boxB sequence present on a scaffold RNA [33]. The scaffold RNA was in turn base-paired to a specific short RNA sequence, such as an RNA aptamer. A number of RNA scaffolds based on the design of the AriBo tag scaffold [33] were designed and tested. These RNA scaffolds are referred to as Ab2b, 
$\mathrm{Ab} 2 \mathrm{bA}, \mathrm{Aab}, \mathrm{Ab}$ and $\mathrm{bA}$, respectively. The scaffold RNAs were generated by in vitro transcription, using the DNA templates shown in Figure S1. They contained either one or three copies of the boxB RNA motif [31] to mediate the binding of the scaffolds to a $\lambda \mathrm{N}$ domain [34]. The scaffolds used also contained a complementary sequence to allow the binding of the RNA sequences via base pairing.

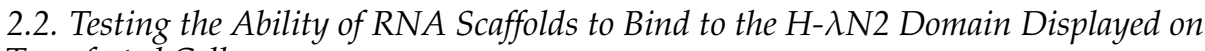 Transfected Cells}

To display $\lambda \mathrm{N}$ protein domains on the HEK 293T cells, a recombinant plasmid encoding two copies of an affinity-enhanced $\lambda \mathrm{N}$ protein domain, referred to as $\lambda \mathrm{N} 22$ $(\mathrm{G} 1, \mathrm{~N} 2, \mathrm{~K} 4)[35]$, was used. This domain is referred to here as $\lambda \mathrm{N} 2$. The $\lambda \mathrm{N} 2$ protein was fused in-frame to the C-terminal end of a mutant version of the MV H protein $[20,36]$. The resulting fusion protein is referred to as $\mathrm{H}-\lambda \mathrm{N} 2$. To assess the capacity of the $\mathrm{H}-\lambda \mathrm{N} 2$ protein displayed on the cells that were to bind to the scaffold RNAs via the boxB sequences, the HEK 293T cells were transiently transfected with an H- $\lambda$ N2-encoding plasmid. The controls included plasmids encoding the MV H protein fused to IL-13 [20] or to epidermal growth factor (EGF). The cells were then exposed to various scaffold RNAs base-paired to a DNA oligonucleotide with complementarity to the scaffold RNA sequences and bearing a biotin group at its $5^{\prime}$ end for the subsequent capturing of Phycoerythrin (PE)-tagged streptavidin (SA) (Figure 1A). This DNA oligonucleotide is referred to as Bio oligo. The flow cytometry results presented in Figure 1B show that the strongest PE signal was obtained using the RNA scaffold Ab2bA.

Compared to the HEK 293T cells expressing the H- $\lambda$ N2 protein, only a minor increase in the PE signal was observed in the cells transfected with control plasmids expressing the MV H protein fused either to IL-13 or EGF (Figure 1B). Furthermore, the AriBo tag that lacked sequence complementarity with the Bio oligo did not produce a signal above background levels (Figure 1B). These results support the view that scaffold binding to cells was specifically mediated by the $\mathrm{H}-\lambda \mathrm{N} 2$ protein.

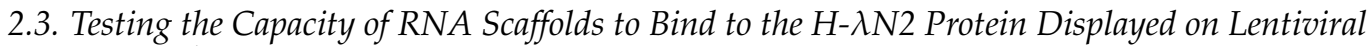 Vector Particles}

To determine the scaffold binding to the $\mathrm{LV}$ vector particles, a mutated version of the MV $H$ protein $[20,36]$ bound to the $\lambda \mathrm{N} 2$ protein was used. $L V$ vector particles bearing the $\mathrm{H}-\lambda \mathrm{N} 2$ protein and containing the RNA scaffolds shown in Figure 1B were immobilized on streptavidin-coated magnetic beads via the Bio oligo.

The EGFP-encoding LV vector particles pseudotyped with the H- $\lambda \mathrm{N} 2$ (or H-EGF) and VSV-G glycoproteins were used to monitor the transduction of human skin epidermoid carcinoma epithelial A431 cells (Figure 2A). The percentage of EGFP-positive cells was determined by using flow cytometry. The results presented in Figure 2B show that the highest percentage of EGFP-positive cells was obtained using the $\mathrm{bA}$ and $\mathrm{Ab}$ scaffolds that bore boxB motifs either at the $5^{\prime}(\mathrm{bA})$ or $3^{\prime}(\mathrm{Ab})$ ends. The percentage of EGFP-positive cells in both cases reached up to $90 \%$. Using the H-EGF-bearing control vector, the percentage of EGFP-positive A431 cells was $\sim 5 \%$ (Figure 2B). These results are consistent with the view that the $\mathrm{H}-\lambda \mathrm{N} 2$ protein displayed on vector particles specifically mediated the binding of the RNA scaffold/Bio oligo complexes to the vector. 
A

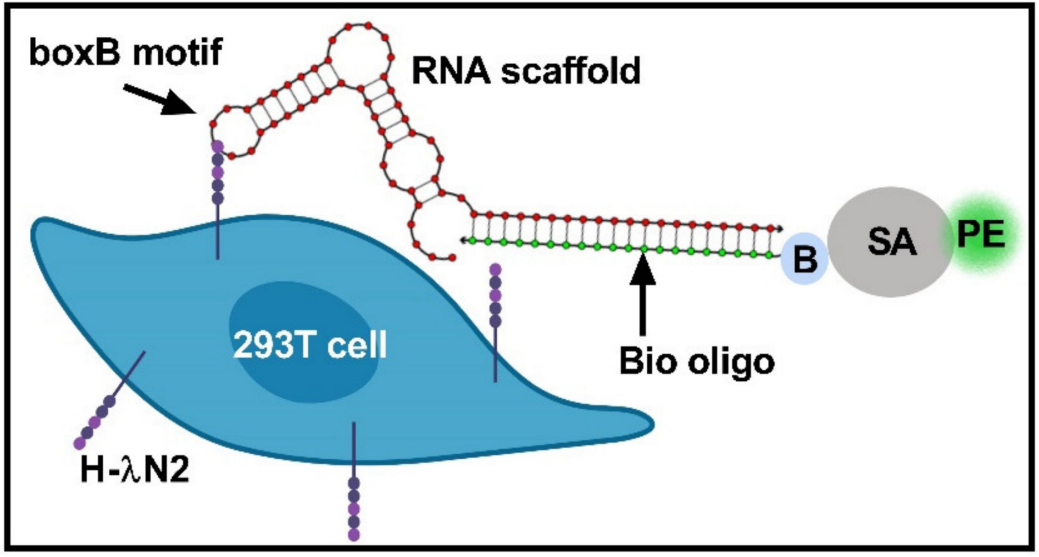

B

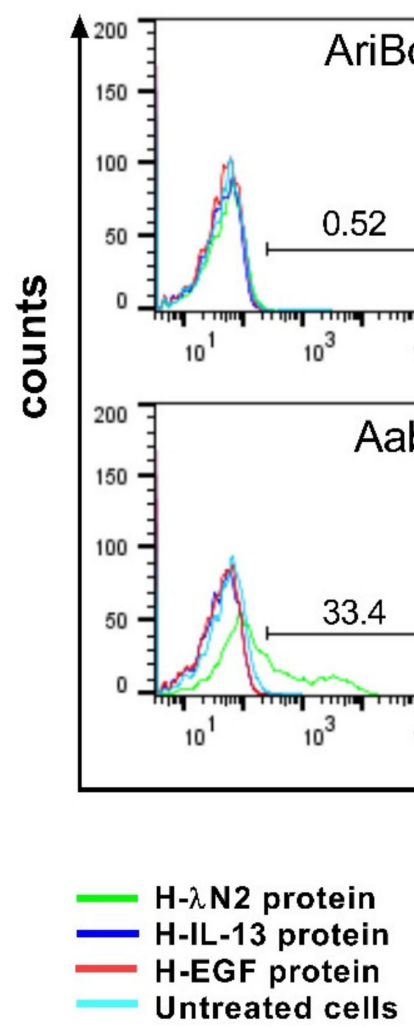

Figure 1. RNA scaffold binding to the $\mathrm{H}-\lambda \mathrm{N} 2$ protein, a RNA binding domain derived from the bacteriophage lambda antitermination protein $\mathrm{N}$ fused to the MV H protein in transfected HEK 293T cells. (A) Outline of the approach to test the binding of RNA scaffolds to the H- $\lambda$ N2 protein displayed on the surface of the transfected HEK 293T cells. The scaffold binding was determined using the Bio oligo in conjunction with the PE-labeled streptavidin (SA-PE). The RNA structure depicted was created from random sequences using the NUPACK Web Application [37]. (B) Representative flow cytometry profiles of transfected HEK 293 T cells expressing H- $\lambda$ N2, H-IL-13, or H-EGF, and treated with various RNA scaffolds bound to the Bio oligo. The numbers refer to the percentage of PE-positive cells observed with the various scaffolds. Untreated cells: cells not exposed to an RNA scaffold, the Bio oligo or SA-PE. 
A

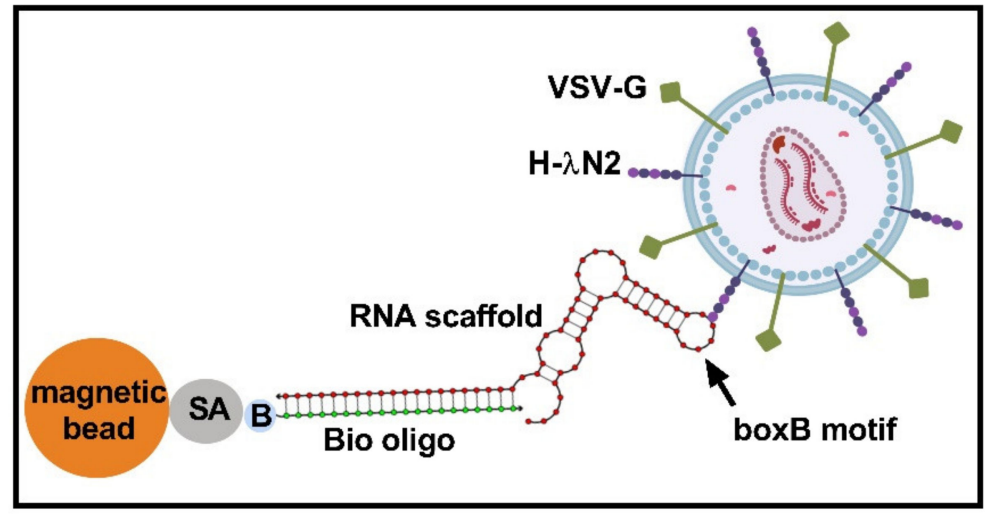

B

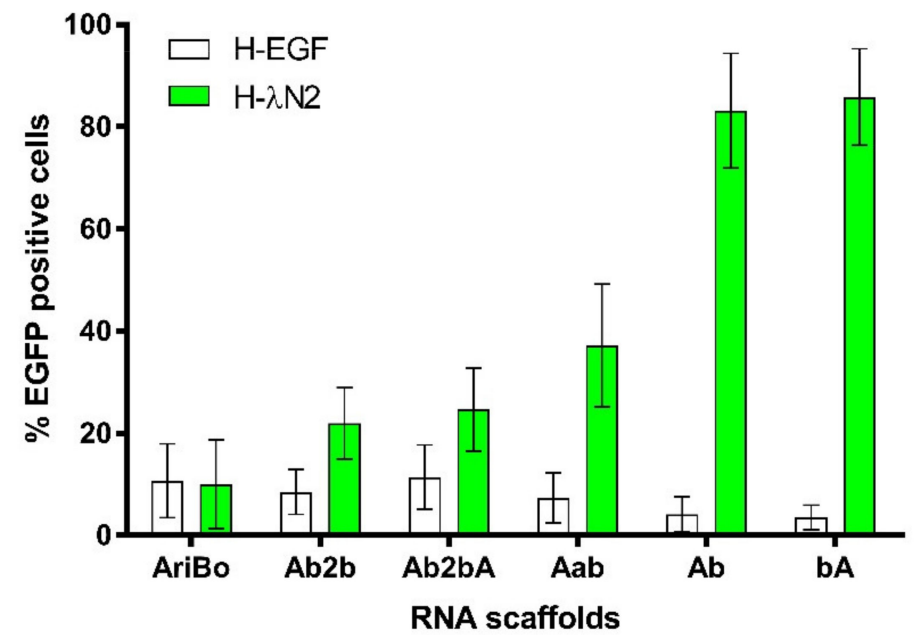

Figure 2. Testing of RNA scaffold binding to the $\mathrm{H}-\lambda \mathrm{N} 2$ protein displayed on lentiviral vector particles. (A) Outline of the approach to test the scaffold binding to the LV vector particles displaying the H- $\lambda$ N2 plus VSV-G proteins. The vectors containing H-EGF instead of $\mathrm{H}-\lambda \mathrm{N} 2$ were used as a control. The vectors were exposed to RNA scaffolds immobilized on streptavidin-coated magnetic beads via the Bio oligo. (B) To determine the transduction efficiencies, magnetic beads with LV vector particles attached were added to A431 cells and the percentage of EGFP-positive cells was determined by using flow cytometry three days later. The error bars represent the means $\pm \mathrm{SD}$ of three independent experiments.

\subsection{RNA Scaffold Binding to RNA Aptamers}

To test the ability of the RNA scaffolds described above to bind to other RNA sequences, a J18 RNA aptamer-based sequence was used. The J18 aptamer was previously shown to bind to human EGFR [38-40]. The J18 RNA aptamer was generated by in vitro transcription using the DNA template shown in Figure S2. To test the aptamer's ability to bind to EGFR, the A431 cell line that expressed high levels of EGFR [41] was used. The presence of EGFR on the A431 cells was confirmed by anti-EGFR antibody binding, and the specificity of the antibody binding was assessed by adding increasing amounts of recombinant EGF (rEGF), recombinant EGFR (rEGFR), or an isotype antibody control (Figure S3). The J18 aptamer was extended at its $3^{\prime}$ end with a sequence (5' GAAUUAAAUGCCCGCCAUGACCAG $3^{\prime}$ ) [38], allowing it to bind to a complementary DNA oligonucleotide, referred to as oligo Bio, bearing a biotin group at its $5^{\prime}$ end for the subsequent capture of PE streptavidin. The binding of J18 aptamer/oligo Bio/PE streptavidin complexes to the A431 cells was assessed using flow cytometry. In a manner that was consistent with earlier findings reported by Li et al. [38,39], the flow cytometry analysis showed that aptamer J18 was capable of binding to A431 cells (Figure 3A). Our results also showed that the exposure of the A431 cells to the J18 aptamer in the presence of rEGF or rEGFR resulted in diminished flow cytometry signals (Figure $3 \mathrm{~A}$, left and right panels, respectively). This 
finding is consistent with the view that the J18 aptamer binds to EGFR and that adding soluble rEGFR or rEGF competes with the aptamer binding to cells.

A

A431 cells

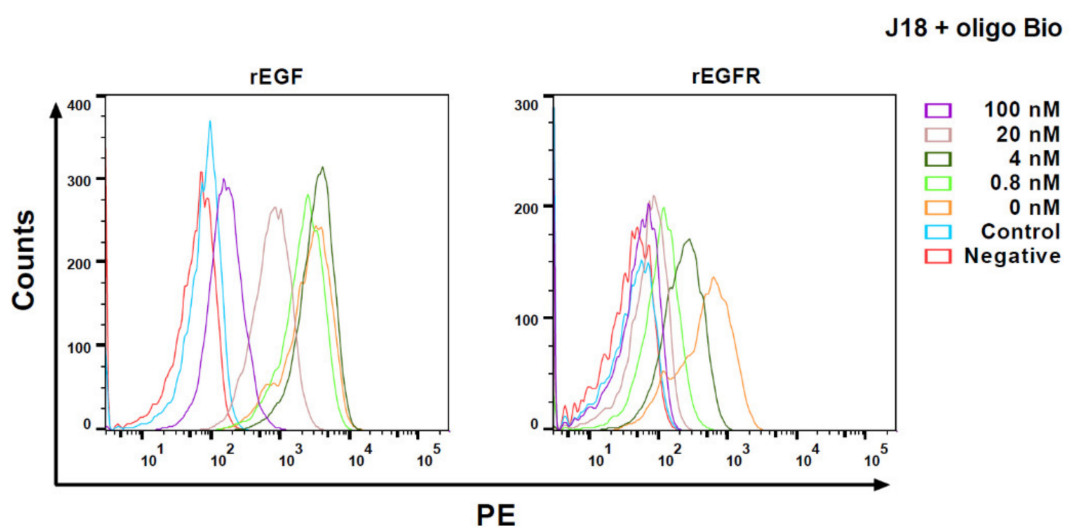

B

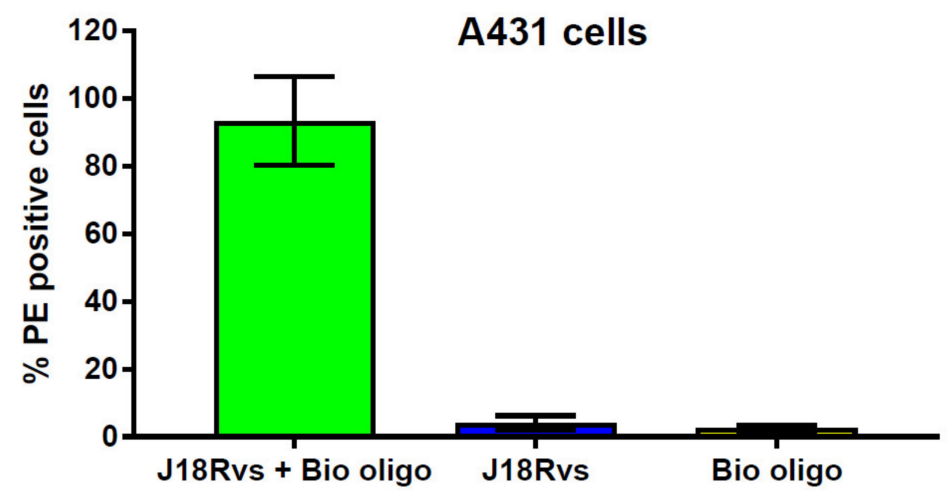

C

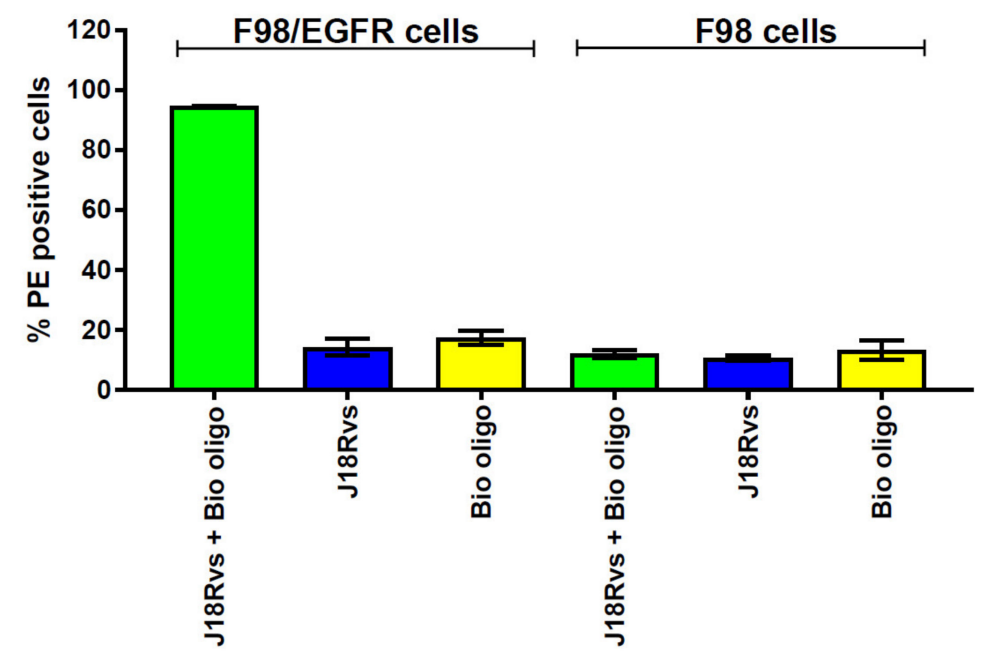

Figure 3. RNA aptamer binding to A431 cells and F98/EGFR cells. (A) J18 aptamer binding to A431 cells in the presence of rEGF ranging from $0 \mathrm{nM}$ to $100 \mathrm{nM}$ (left panel) or rEGFR ranging from $0 \mathrm{nM}$ to $100 \mathrm{nM}$ (right panel). Control: SA19 aptamer directed against streptavidin. The aptamer binding was assessed using the oligo Bio bound to the PE streptavidin. Negative: cells not exposed to the J18 aptamer. (B) J18 Rvs aptamer binding to A431 cells. The aptamer binding was determined using the Bio oligo bound to the PE streptavidin. (C) J18 Rvs aptamer binding to F98/EGFR and F98 cells. Green panels: cells plus J18 Rvs aptamer plus Bio oligo; blue panels: cells plus J18 Rvs aptamer; yellow panels: cells plus Bio oligo. The error bars represent the means \pm SD of three independent experiments. 
An RNA aptamer (SA19) directed against streptavidin [42] was used as a negative control. It was generated by in vitro transcription, using the DNA template shown in Figure S2. The SA19 aptamer binding produced a flow cytometry signal at background levels (Figure 3A, Control) as did the binding of a scrambled RNA aptamer (results not shown). Furthermore, the co-incubation of the cells with the RiboShredder ${ }^{\mathrm{TM}}$ RNase Blend resulted in a complete loss of fluorescence (results not shown), indicating that the flow cytometry signals observed were mediated by the RNA.

The J18 Rvs aptamer, a modified version of the J18 aptamer, was used to assess the scaffold binding. It was generated by in vitro transcription, using the DNA template shown in Figure S2. The results presented in Figure 3B show that the J18 Rvs aptamer retained its capacity to bind to A431 cells, while the scrambled RNA aptamer did not (Figure S4).

The J18 Rvs aptamer also bound to rat F98 cells expressing human EGFR (referred to as F98/EGFR cells) [43], but not to F98 cells lacking an EGFR-coding region (Figure 3C). The omission of the Bio oligo or the aptamer resulted in PE signals at background levels (Figure $3 \mathrm{~B}, \mathrm{C}$ ).

\subsection{Assessing the Functionality of RNA Aptamer/Scaffold Complexes}

The capacity of the various scaffold RNAs to bind to $\lambda \mathrm{N}$ protein sequences was tested next. To do this, aptamer/scaffold complexes were mixed with a synthetic $\lambda \mathrm{N}$ peptide bound to FITC (referred to as $\lambda$ N-FITC peptide) (Figure 4A). The A431 cells containing aptamer/scaffold $/ \lambda$ N-FITC peptide complexes were subjected to a flow cytometry analysis. For the Ab2bA RNA scaffold, a difference of up to four-fold in the mean fluorescence intensity (MFI) values over those involving cells treated with the $\lambda \mathrm{N}$-FITC peptide alone was observed (Figure 4B), while the differences observed with the Ab2b, Aab, Ab and bA scaffolds were less pronounced (Figure 4B). In the samples treated with rEGFR or RNase or by using the AriBo tag scaffold that lacked a complementary sequence for aptamer binding, the differences in the MFI values observed were smaller (Figure 4B). This result is consistent with the view that the flow cytometry signals observed were due to the binding of the J18 Rvs aptamer/scaffold/ $\lambda$ N-FITC peptide complexes to the EGFR on the A431 cells.

The binding specificity of the aptamer/scaffold $/ \lambda$ N-FITC peptide complex was assessed in more detail by comparing the ability of the J18 Rvs aptamer/Ab2bA RNA scaffold/ $\lambda$ N-FITC complex and the SA19 aptamer/Ab2bA RNA scaffold/ $\lambda$ N-FITC complex to bind to A431 cells and to the MDA-MB-435 cells that lacked EGFR [39]. The results presented in Figure S5 show that for the A431 cells treated with the J18 Rvs aptamer/Ab2bA RNA scaffold $/ \lambda \mathrm{N}$-FITC complex or the $\lambda \mathrm{N}$-FITC peptide alone, the difference in the MFIs was about four-fold, while for the A431 cells exposed to the SA19 aptamer/Ab2bA RNA scaffold $/ \lambda \mathrm{N}$-FITC complex or the $\lambda \mathrm{N}$-FITC peptide alone, there was no difference detected in the MFI values. For the MDA-MB-435 cells treated with the J18 Rvs aptamer/Ab2bA RNA scaffold/ $\lambda$ N-FITC complex or the SA19 aptamer/Ab2bA RNA scaffold/ $\lambda$ N-FITC, complex there was no difference in the MFIs, indicating that J18 Rvs aptamer binding to the A431 cells was specific.

It was interesting to note that the RNA scaffold binding to the $\mathrm{H}-\lambda \mathrm{N} 2$ protein displayed on the $\mathrm{LV}$ vector particles was highest with the $\mathrm{Ab}$ and $\mathrm{bA}$ scaffolds (Figure $1 \mathrm{~B}$ ), while the results presented in Figure 4B show that in the context of the transfected A431 cells expressing the $\mathrm{H}-\lambda \mathrm{N} 2$ protein, the strongest signal was obtained using the RNA scaffold $\mathrm{Ab} 2 \mathrm{bA}$. The reasons for this discrepancy are not clear. There may have been differences in the accessibility of the bulkier Ab2bA RNA scaffold to the $\mathrm{H}-\lambda \mathrm{N} 2$ protein displayed on the vector particles compared to the transfected A431 cells. 

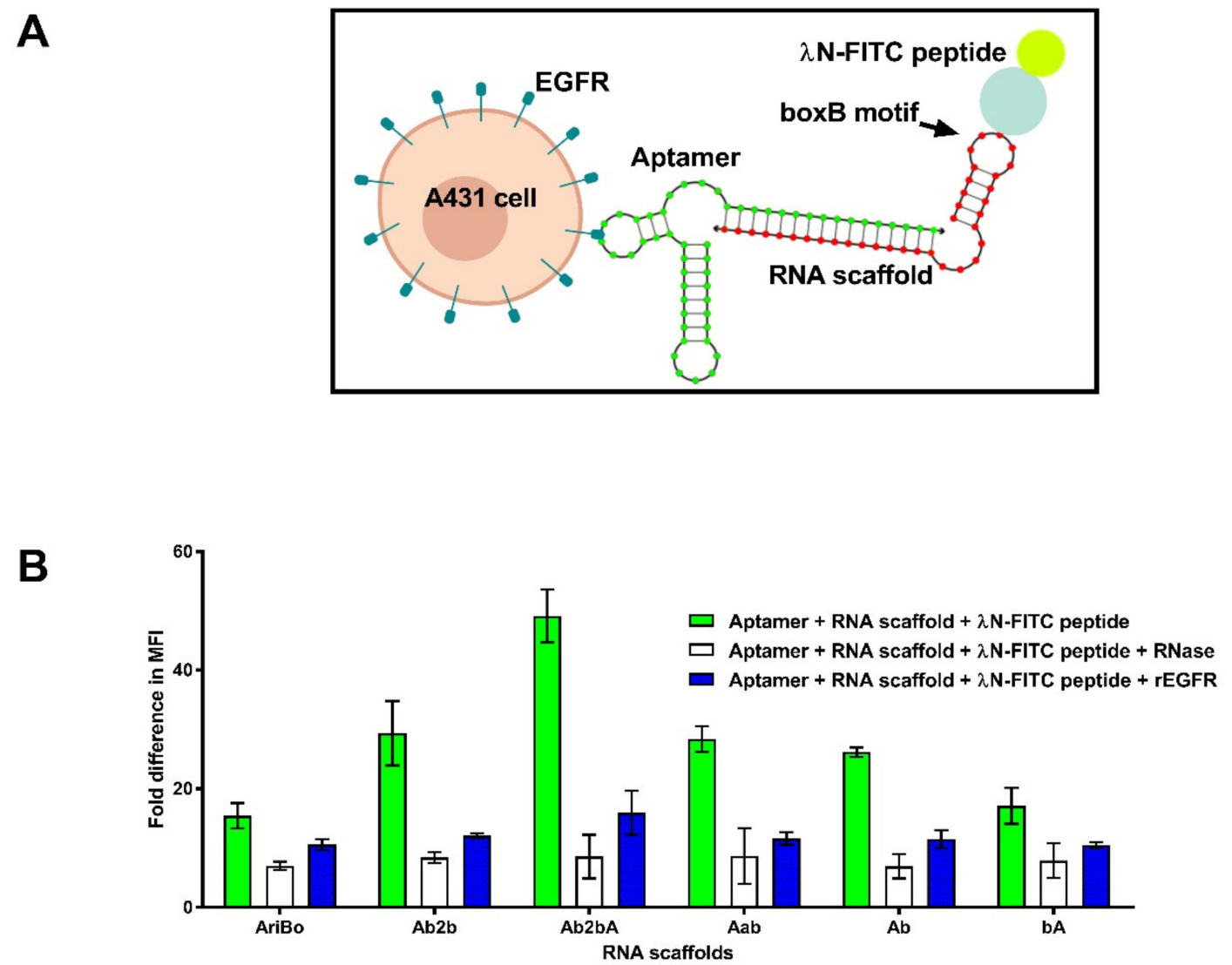

Figure 4. Testing of RNA scaffolds designed to bind the J18 Rvs aptamer and the bacteriophage $\lambda$ N protein. (A) Outline of the scaffold binding approach involving the J18 Rvs aptamer and the $\lambda$ N-FITC peptide. (B) Binding of aptamer/scaffold/ $/ \lambda N$ FITC peptide complexes to the A431 cells analyzed by flow cytometry. The green bars refer to the binding to the A431 cells of the J18 Rvs aptamer in combination with an RNA scaffold and the $\lambda$ N-FITC peptide. The open bars refer to samples treated with $\sim 0.02 \mathrm{U} / \mu \mathrm{L}$ of RiboShredder RNase blend prior to flow cytometry. The blue bars refer to the samples treated using rEGFR $(1 \mu \mathrm{M})$. The binding of the aptamer/scaffold/ $\lambda \mathrm{N}$-FITC complexes to the cells was carried out as described in Section 4. The fold differences in MFI refer to the MFI signal obtained with a particular aptamer/scaffold/ $\lambda$ N-FITC peptide complex compared to the MFI signal observed with the cells treated with $\lambda$ N-FITC peptide alone. The error bars represent mean $\pm \mathrm{SD}$ of two independent experiments.

\section{Discussion}

Different protein ligands, such as EGF [19], IL-13 [20,44], single-chain antibodies [21], and designed ankyrin repeat proteins (DARPins) [22], have been successfully displayed on $\mathrm{LV}$ vector particles in the past, allowing $\mathrm{LV}$ vector delivery to specific target cells in vitro and in vivo [18]. Nucleic acid aptamers capable of binding to a variety of targets, including extracellular ligands and cell surface proteins, have been developed $[45,46]$ and used successfully to mediate the uptake into cells of siRNAs, chemotherapeutic agents, cell toxins, and nanoparticles $[47,48]$, but approaches involving nucleic acid-based aptamers in the retargeting of $\mathrm{LV}$ vector transduction have not been described so far. The potential advantage of the nucleic acid aptamer approach over traditional protein ligand approaches is that nucleic acid-based aptamers are easier to prepare and structurally more flexible compared to antibody or peptide-based ligands.

Methods aimed at the attachment of short nucleic acid sequences to $\mathrm{LV}$ vector particles in a specific and tight fashion have not been reported thus far. The work described in this study describes a novel approach to the tethering of RNA aptamers to LV vector particles based on the bacteriophage $\lambda \mathrm{N} /$ boxB system [49]. The bacteriophage $\lambda \mathrm{N} /$ boxB system is attractive because of the small size of the $\mathrm{N}$ protein domain $(12.2 \mathrm{kDa})$. Of the 107 amino acids that constitute the N protein, only the 22 amino acid residues of the RNA- 
binding domain are crucial for RNA recognition [31,32]. A synthetic peptide consisting of these amino acids was found to bind the boxB element with high picomolar affinity and specificity, similar to that of its full-length counterpart [35].

The bacteriophage MS2 coat protein system is the most widely used RNA tethering system [50]. The popularity of the bacteriophage MS2 tethering system is based on its physical and functional characteristics: (1) the MS2 coat protein is relatively small (14 kDa, 129 amino acids), (2) it binds its 21-nucleotide RNA hairpin target with high affinity and selectivity, potentially limiting off-target binding, and (3) the MS2 hairpin-MS2 coat protein interaction is well characterized [51]. The potential advantages of the $\lambda \mathrm{N} /$ boxB system over other MS2 coat protein systems are that the $\lambda \mathrm{N}$ protein domain is smaller and that it binds to RNA as a monomer, unlike the MS2 coat protein, which binds as a dimer [31].

Our results show that the $\lambda \mathrm{N} /$ boxB system provides a promising approach to the attachment of short RNA sequences to LV vector particles. In addition, it has the potential to bind short DNA sequences, including DNA aptamers, via a boxB-containing complementary RNA. Our results also show that the binding of the various boxB-containing RNA scaffolds and aptamer sequences to $\lambda \mathrm{N}$ protein sequences was specific. In addition, the $\mathrm{H}-\lambda \mathrm{N} 2$ protein displayed on the LV vector particles, along with the VSV-G, allowed the transduction of A431 cells. Replacing the VSV-G with smaller fusion domains, including the VSV-GS domain [52] may ultimately increase the specificity of this approach.

The limitation of the RNA-capturing approach described in this study is that the high prevalence of antibodies against measles virus proteins may hamper the efficacy of LV vectors containing engineered measles virus $\mathrm{H}$ glycoproteins, including $\mathrm{H}-\lambda \mathrm{N} 2$, in a clinical setting, due to vaccination or natural infection [53]. Glycoproteins from other members of the Paramyxoviridae family, including those derived from the Tupaia paramyxovirus (TPMV) have also been used to pseudotype LV vectors [54]. The absence of pre-existing human antibodies positions TPMV glycoproteins as attractive candidates for the design of specific and directed LV vector pseudotyping strategies. In addition, $L V$ vectors pseudotyped with VSV-G are known to be sensitive to complement-mediated inactivation by human serum [26]. The use of alternative vesiculovirus G glycoproteins derived from Cocal virus, Maraba virus or Piry virus may help prevent this pre-existing humoral immunity issue [27]. The impact on the innate response evocated by systemic injection of LV particles exposing short RNAs also needs to be considered [55]. CpG sequences alone or in longer DNA and RNA oligonucleotides can behave like pathogen-associated molecular patterns and trigger an innate immune response, leading to cytokine production via Toll-like receptors. Strategies to ameliorate or eliminate damaging CpG effects have included the methylation of cytosines in the aptamer, the truncation of the aptamer to its essential binding site, and backbone modifications to lessen the toxic CpG effect on innate immunity [56].

In future studies we plan to determine the usefulness of RNA and DNA aptamers tethered to $\mathrm{LV}$ vector particles via the $\lambda \mathrm{N}$ protein-boxB system for targeted transduction in vitro and in vivo $[20,54]$. We also plan to investigate whether short RNA and DNA oligonucleotides bound to $L V$ vector particles via the $\lambda \mathrm{N}$ protein-boxB system can be used to shield $L V$ vectors against neutralizing antibodies and complement attack.

\section{Materials and Methods}

\subsection{Plasmid Constructs}

A synthetic DNA sequence (GenScript USA, Piscataway, NJ, USA) encoding the $\lambda N 2$ protein (GNAKTRRRERRAEKQAQWKAANGAGAGAGAGAGAGNAKTRRRERRAEKQAQWKAAN) $[33,35]$ was subcloned into plasmid pCG-Hc $\Delta 18-A A-I L-13$ [20], replacing the IL-13 coding region. The resulting plasmid is referred to as pCG-Hc $\Delta 18$ AA- $\lambda$ N2. The DNA sequence encoding human EGF (GenScript USA) was subcloned into pCG-Hc $\Delta 18$-AA-IL-13 [20], resulting in plasmid pCG-Hc $\Delta 18-A A-E G F$. Recombinant pUC57-based plasmids encoding the J18 and J18 Rvs and scrambled RNA aptamers, the SA19 aptamer [42], the ARiBo tag [33], and the Ab2b, Ab2bA, Aab, Ab and bA RNA scaffolds, were provided by GenScript USA. 
The pNL (CMV)EGFP/CMV/WPRE $\Delta \mathrm{U} 3 \mathrm{LV}$ vector plasmid was described previously [20]. It is available through Addgene, Watertown, MA (plasmid \#41970).

\subsection{Cells}

The A431 cells (ATCC CRL-1555, Manassas, VA, USA), MDA-MB-435 cells (ATCC HTB-129), HEK 293T cells (ATCC CRL-3216), F98 cells and F98/EGFR cells (ATCC CRL2397 and CRL-2948, respectively) were grown in Dulbecco's Modified Eagle's Medium (DMEM) containing high glucose ( $4.5 \mathrm{~g} / \mathrm{L}), 2 \mathrm{mM}$ L-glutamine, $10 \%$ heat inactivated fetal bovine serum (FBS), $100 \mathrm{U} / \mathrm{mL}$ penicillin and $100 \mu \mathrm{g} / \mathrm{mL}$ streptomycin. The cell culture reagents were purchased from Gibco (Thermo Scientific, Waltham, MA, USA).

\subsection{Lentiviral Vector Production}

The LV vector production was carried out using $15-\mathrm{cm}$ plates (Nunc, Thermo Scientific, Waltham, MA, USA). One day before transfection, $6 \times 10^{6} 293 \mathrm{~T}$ cells were seeded into each $15 \mathrm{~cm}$ plate. The vector production was carried out via PEI-mediated transfection [57] of $7.65 \mu \mathrm{g}$ of $\mathrm{pNL}(\mathrm{CMV}) \mathrm{EGFP} / \mathrm{CMV} / \mathrm{WPRE} \Delta \mathrm{U} 3$ vector plasmid [20], $5.1 \mu \mathrm{g} \mathrm{pCD} / \mathrm{NL}-$ $\mathrm{BH}^{*} \Delta \Delta \Delta$ packaging plasmid [58], $1.95 \mu \mathrm{g}$ of pCEF-VSV-G plasmid [20] and $0.6 \mu \mathrm{g}$ of the pCG-Hc $\Delta 18-A A-\lambda N 2$ or pCG-Hc $\Delta 18$-AA-EGF plasmids [20] per $15 \mathrm{~cm}$ dish. The medium was replaced the following day with $15 \mathrm{~mL}$ of Ultraculture medium per $15 \mathrm{~cm}$ dish (Lonza, Walkersville, MD, USA), supplemented with $2 \mathrm{mM} \mathrm{L-glutamine,} 100 \mathrm{U} / \mathrm{mL}$ penicillin and $100 \mu \mathrm{g} / \mathrm{mL}$ streptomycin. The $\mathrm{LV}$ vector-containing medium was collected 3 days post-transfection and passed through a 0.45 um filter unit. To concentrate the vectors, the medium was mixed 3:1 with Lenti- $X^{\mathrm{TM}}$ lentiviral concentrator (Takara Bio USA, Inc., Mountain View, CA, USA). The mixture was incubated at $4{ }^{\circ} \mathrm{C}$ for $4 \mathrm{~h}$ and then centrifuged at $3000 \times g$ for $45 \mathrm{~min}$ at $4{ }^{\circ} \mathrm{C}$. The pellets were resuspended in $1 / 10$ th of the original volume using a $100 \mathrm{mM}$ HEPES buffer ( $\mathrm{pH}$ 7.5) plus $0.2 \mathrm{U} / \mu \mathrm{L}$ of RNase inhibitor (RiboGuard ${ }^{\mathrm{TM}}$, Lucigen, Middleton, WI, USA). By contrast, the vectors were concentrated by ultracentrifugation, as described by Kutner, et al. [59].

\subsection{Production of Aptamer and Scaffold RNAs}

The recombinant plasmids encoding the RNA scaffold and the aptamer sequences were linearized using the restriction enzymes referred to in Supplementary Figures S1 and S2 respectively. The in vitro RNA synthesis was carried out for $5 \mathrm{~h}$ at $37^{\circ} \mathrm{C}$ using an Ampliscribe Kit (Epicentre, Madison, WI, USA). The residual plasmid DNA was degraded using $0.05 \mathrm{U} / \mu \mathrm{L}$ of DNase I (Epicentre) at $37^{\circ} \mathrm{C}$ for $15 \mathrm{~min}$. The RNAs were concentrated by ethanol precipitation and fractionated on $8 \%$ polyacrylamide gels containing $8 \mathrm{M}$ urea (Thermo Scientific). The RNA bands were visualized by UV shadowing, using Fluor-coated TLC plates (Ambion Inc., Austin, TX, USA). The excised gel bands were frozen at $-80^{\circ} \mathrm{C}$ for $15 \mathrm{~min}$, crushed using a pellet pestle (Thermo Scientific), and suspended in a TE buffer. Subsequently, the samples were heated at $73^{\circ} \mathrm{C}$ for $15 \mathrm{~min}$ and a RiboGuard ${ }^{\mathrm{TM}}$ RNase inhibitor (Lucigen) (40 U/tube of in TE buffer) was added. The samples were incubated overnight at $37^{\circ} \mathrm{C}$ with constant shaking. The extracted RNAs were recovered by filtration, using a $0.45 \mu \mathrm{m}$ filter (Millipore, Billerica, MA, USA), followed by ethanol precipitation. The RNA pellets were resuspended in the TE buffer. By contrast, the RNAs were purified and concentrated using an RNA Clean \& Concentrator ${ }^{\mathrm{TM}}-5$ kit (Zymo Research, Irvine, CA, USA).

\subsection{Binding of J18 and J18 Rus Aptamers to Cells}

For cell binding, the J18 RNA aptamer (5' GGCGCUCCGACCUUAGUCUCUGCAAGAUAAACCGUGCUAUUGACCACCCUCAACACACUU-AUUUAAUGUAUUGAACGGACCUACGAACCGUGUAGCACAGCAGAGAAUUAAAUGCCCGCCA-UGACCAGAU $\left.3^{\prime}\right)$ was bound to a complementary single-stranded DNA oligonucleotide bearing a biotin group at the $5^{\prime}$ end (IDT, Coralville, IA, USA), using RNA/DNA hybridization. The oligonucleotide used is referred to as oligo Bio (5' Bio-TGGTCATGGCGGGCATTTAATT $3^{\prime}$ ). 
The J18 Rvs aptamer, a modified version of the J18 aptamer, was used to assess the scaffold binding. It consisted of the original J18 aptamer sequence but contained a different sequence (5' GUGGUCAUGGCGGGCAUUUAAUU $3^{\prime}$ ) at its $3^{\prime}$ end. To investigate the binding of the J18 Rvs RNA aptamer to the cells, a complementary single-stranded DNA oligonucleotide, referred to as Bio oligo (5' Bio-AATTAAATGCCCGCCATGACCA $3^{\prime}$ ) was used. One-toone molar ratios of the oligo Bio plus the J18 aptamer, or the Bio oligo plus the J18 Rvs aptamer were used. The controls included an RNA aptamer (SA19) directed against streptavidin [42] (5' GGGAGACAAGACUAGACGCUCAACUUUCCTAGCGCACAUGCGACCUCUAUGCGUAAUACGAACGUUGACGGUUCGACAUGAGACUCACAACAGUUCCCUUUAGUGAGGGUUAAUUCUGGUCAUGGCGGGCAUU-UAAUUGA $3^{\prime}$ ), as well as a scrambled RNA aptamer (5' GGCGCUCCGACCUUAGUCUCUGUACAGAUCCCAUUCUAUACCCAAAUAACUGUAAAUUAUGACGUACGCCUCCCAUCG-

AAGAGUGAACCGUGUAGCACAGCAGAGAAUUAAAUGCCCGCCAUGACCAGA 3).

The formation of RNA/DNA hybrids involved heating the samples for $3 \mathrm{~min}$ at $73{ }^{\circ} \mathrm{C}$, with a subsequent gradual decrease in temperature to $25^{\circ} \mathrm{C}$. Next, the RNA/DNA hybrids were incubated at $25^{\circ} \mathrm{C}$ for $15 \mathrm{~min}$ with a streptavidin R-phycoerythrin conjugate (SA-PE) (Molecular Probes, Life Sciences, Grand Island, NY, USA), using a molar ratio of 2:1. To analyze aptamer binding, A431, MDA-MB-435 cells, F98/EGFR cells or F98 cells were trypsinized using $0.25 \%$ Trypsin-EDTA (Thermo Scientific) and washed three times with a DPBS $/ 5 \mathrm{mM} \mathrm{MgCl}_{2}$ buffer. For the labeling of the cells, the RNA/DNA/SA-PE complexes were diluted in DPBS/ $5 \mathrm{mM} \mathrm{MgCl} 2$ and added to the cells. Binding assays were carried out for $30 \mathrm{~min}$ at room temperature in the dark. The samples were then washed with DPBS $/ 5 \mathrm{mM} \mathrm{MgCl}_{2}$ and analyzed using flow cytometry.

To assess the specificity of the J18 aptamer binding, rEGFR (ACRO Biosystems, Newark, DE) or rEGF (GenScript USA, Piscataway, NJ, USA) in $\mathrm{H}_{2} \mathrm{O} / 0.1 \%$ BSA were added to compete for aptamer binding to the EGFR. An aptamer that does not bind to EGFR (SA19) was used as an additional control for specificity.

\subsection{RNA Scaffold Binding to Cells Displaying the $H-\lambda N 2$ Protein}

To test the ability of the various RNA scaffolds to bind to MV H- $\lambda$ N2 proteins displayed on the surface of cells, the HEK 293T cells were transfected using the pCG-Hc $\Delta 18-\mathrm{AA}-\lambda \mathrm{N} 2$ plasmid. The plasmids pCG-Hc $\Delta 18-A A-I L-13$ and pCG-Hc $\Delta 18-A A-E G F$ were used as controls. The day before transfection, $2 \times 10^{5}$ HEK 293T cells per well were seeded in six well-plates. The next day, the medium was replaced and $1 \mu \mathrm{g}$ of the pCG-Hc $\Delta 18-\mathrm{AA}-\lambda \mathrm{N} 2$, pCG-Hc $\Delta 18$-AA-IL-13 or pCG-Hc $\Delta 18$-AA-EGF plasmid DNAs in $150 \mathrm{mM}$ were mixed at a $1: 1(v / v)$ ratio with $12.6 \% \mathrm{PEI}$ in $150 \mathrm{mM} \mathrm{NaCl}$, and the DNA/PEI mixture was added to the wells [57]. Forty-eight hours later, the transfected cells were detached from the wells using $\mathrm{Ca}^{++}$, and $\mathrm{Mg}^{++}$free PBS containing $0.5 \mathrm{mM}$ EDTA and $50 \mathrm{mM} \mathrm{NaCl}$. The cells were washed three times using PBS and $2 \times 10^{5}$ cells were incubated in the dark for $30 \mathrm{~min}$ at room temperature, using a $50 \mathrm{nM}$ solution containing the RNA scaffold base-paired to the Bio oligo, which was bound to SA-PE in a $50 \mathrm{mM}$ HEPES buffer $\mathrm{pH}$ 7.5 (total volume: $20 \mu \mathrm{L}$ ). After washing using the $50 \mathrm{mM}$ HEPES buffer, the cells were analyzed using flow cytometry.

\subsection{Binding of RNA Scaffolds to the J18 Rvs Aptamer and the $\lambda N$ Peptide}

The RNA aptamers and scaffolds were mixed and base pairing was initiated via the conditions used for the binding the J18 Rvs aptamer to the Bio oligo. To do this, $100 \mu \mathrm{L}$ of a $0.15 \mu \mathrm{M}$ solution containing the J18 Rvs aptamer, plus the RNA scaffold in DPBS/5 mM $\mathrm{MgCl}_{2}$, was mixed with $100 \mu \mathrm{L}$ of a $30 \mu \mathrm{M}$ solution of the $\lambda \mathrm{N}$ peptide conjugated to FITC (FITC-GNAKTRRRERRAEKQAQWKAAN) (Genscript) in DPBS/5 mM MgCl 2 , and incubated for $20 \mathrm{~min}$ at $25^{\circ} \mathrm{C}$. For the cell binding, $60 \mu \mathrm{L}$ of the J18 Rvs aptamer/RNA scaffold $/ \lambda$ N-FITC complex were added to $2 \times 10^{5}$ trypsinized A431 or MDA-MB- 435 cells and the cells were incubated for $30 \mathrm{~min}$ at room temperature in the dark. To determine the specificity of the aptamer binding, $6 \mu \mathrm{L}$ of a $0.1 \mu \mathrm{M}$ rEGFR (ACRO Biosystems, Newark, 
DE) solution in $\mathrm{H}_{2} \mathrm{O} / 0.1 \%$ BSA were added to compete for aptamer binding to the EGFR on the A431 cells. Treatment with $0.02 \mathrm{U} / \mu \mathrm{L}$ of RiboShredder ${ }^{\mathrm{TM}}$ RNase Blend (Epicentre) on ice was used to confirm that $\lambda \mathrm{N}$ peptide-FITC binding was mediated by the RNA. After incubation for $30 \mathrm{~min}$ at room temperature on ice, the cells were washed three times and analyzed using flow cytometry. As an additional control, the SA19 aptamer that does not bind to EGFR was used.

\subsection{Scaffold Binding to Lentiviral Vectors Displaying the $H-\lambda N 2$ Protein}

The lentiviral vector particles bearing $\mathrm{H}-\lambda \mathrm{N} 2$ proteins were captured using streptavidincoated magnetic beads (Dynabeads ${ }^{\circledR} \mathrm{M}-280$, Thermo Scientific). To do this, the beads (20 $\mu \mathrm{L}$ /sample) were washed three times with DPBS $/ 5 \mathrm{mM} \mathrm{MgCl}_{2}$ and incubated with a $\sim 100 \mathrm{nM}$ solution of a particular RNA scaffold base-paired to the Bio oligo in the presence of $1.3 \mathrm{U} / \mu \mathrm{L}$ of RiboGuard ${ }^{\mathrm{TM}}$ (Lucigen). After shaking for $20 \mathrm{~min}$ at $1300 \mathrm{rpm}$ at room temperature, a $100 \mu \mathrm{L}$ aliquot of the magnetic beads containing RNA scaffolds was mixed with a $100 \mu \mathrm{L}$ aliquot of a $\mathrm{LV}$ vector sample displaying either $\mathrm{H}-\lambda \mathrm{N} 2$ or H-EGF. The titers of the LV vectors displaying the H- $\lambda \mathrm{N} 2$ or H-EGF proteins plus VSV-G were typically around $2 \times 10^{6}$ transducing units per $\mathrm{ml}$. The samples were incubated for one hour at $4{ }^{\circ} \mathrm{C}$, with gentle vortexing every $10 \mathrm{~min}$. The samples were then washed three times and the magnetic beads with bound vector particles were diluted in DMEM containing $8 \mu \mathrm{g} / \mathrm{mL}$ polybrene and added to the A431 cells in six wells-plates, seeded the day before, at a density of $\sim 1 \times 10^{5}$ cells/well. The percentage of transduced cells based on EGFP expression was determined using flow cytometry three days later [59].

Supplementary Materials: The following are available online at https:/ /www.mdpi.com/article / $10.3390 /$ ijms221910263/s1.

Author Contributions: M.P. and J.R. designed the study. M.P. and M.P.M. performed the experiments. M.P., M.P.M. and J.R. analyzed the data. M.P. and J.R. wrote the manuscript. All authors have read and agreed to the published version of the manuscript.

Funding: This work was supported by the Intramural Research Program of the Center for Biologics Evaluation and Research (CBER), U.S. Food and Drug Administration. The project was supported in part by M.P.'s appointment to the Research Participation Program at CBER, administered by the Oak Ridge Institute for Science and Education through the US Department of Education and the U.S. Food and Drug Administration.

Institutional Review Board Statement: Not applicable.

Informed Consent Statement: Not applicable.

Data Availability Statement: The data presented in this study are available in the article and Supplementary Materials.

Acknowledgments: We thank Angela Whatley (FDA/CBER/OTAT) and Brent McCright (FDA/ CBER/OTAT) for helpful comments on the manuscript.

Conflicts of Interest: The authors declare no competing interest.

$\begin{array}{ll}\text { Abbreviations } \\ \text { EGFR } & \text { Epidermal growth factor receptor } \\ \text { EGF } & \text { Epidermal growth factor } \\ \text { IL-13 } & \text { Interleukin-13 } \\ \text { LV } & \text { Lentiviral } \\ \text { MV } & \text { Measles virus } \\ \text { SA } & \text { Streptavidin } \\ \text { PE } & \text { Phycoerythrin } \\ \text { VSV-G } & \text { Vesicular stomatitis virus G protein }\end{array}$




\section{References}

1. Sakuma, T.; Barry, M.A.; Ikeda, Y. Lentiviral vectors: Basic to translational. Biochem. J. 2012, 443, 603-618. [CrossRef]

2. Milone, M.C.; O’Doherty, U. Clinical use of lentiviral vectors. Leukemia 2018, 32, 1529-1541. [CrossRef] [PubMed]

3. Naldini, L. Genetic engineering of hematopoiesis: Current stage of clinical translation and future perspectives. EMBO Mol. Med. 2019, 11, e9958. [CrossRef] [PubMed]

4. Liu, Y.; Chen, X.; Han, W.; Zhang, Y. Tisagenlecleucel, an approved anti-CD19 chimeric antigen receptor T-cell therapy for the treatment of leukemia. Drugs Today 2017, 53, 597-608. [CrossRef]

5. Schuessler-Lenz, M.; Enzmann, H.; Vamvakas, S. Regulators' advice can make a difference: European medicines agency approval of zynteglo for beta thalassemia. Clin. Pharmacol. Ther. 2020, 107, 492-494. [CrossRef] [PubMed]

6. Abramson, J.S.; Palomba, M.L.; Gordon, L.I.; Lunning, M.A.; Wang, M.; Arnason, J.; Mehta, A.; Purev, E.; Maloney, D.G.; Andreadis, C.; et al. Lisocabtagene maraleucel for patients with relapsed or refractory large B-cell lymphomas (TRANSCEND NHL 001): A multicentre seamless design study. Lancet 2020, 396, 839-852. [CrossRef]

7. Munshi, N.C.; Anderson, J.L.D.; Shah, N.; Madduri, D.; Berdeja, J.; Lonial, S.; Raje, N.; Lin, Y.; Siegel, D.; Oriol, A.; et al. Idecabtagene vicleucel in relapsed and refractory multiple myeloma. N. Engl. J. Med. 2021, 384, 705-716. [CrossRef]

8. Cavalieri, V.; Baiamonte, E.; Iacono, M.L. Non-primate lentiviral vectors and their applications in gene therapy for ocular disorders. Viruses 2018, 10, 316. [CrossRef]

9. Somaiah, N.; Block, M.S.; Kim, J.W.; Shapiro, G.I.; Do, K.T.; Hwu, P.; Eder, J.P.; Jones, R.L.; Lu, H.; Ter Meulen, J.H.; et al. First-in-class, first-in-human study evaluating LV305, a dendritic-cell tropic lentiviral vector, in sarcoma and other solid tumors expressing NY-ESO-1. Clin. Cancer Res. 2019, 25, 5808-5817. [CrossRef]

10. Capasso, C.; Hirvinen, M.; Cerullo, V. Beyond gene delivery: Strategies to engineer the surfaces of viral vectors. Biomedicines 2013, 1, 3-16. [CrossRef]

11. Metzner, C.; Kochan, F.; Dangerfield, J.A. Postexit surface engineering of retroviral/lentiviral vectors. BioMed Res. Int. 2013, $2013,253521$. [CrossRef] [PubMed]

12. Lévy, C.; Verhoeyen, E.; Cosset, F.-L. Surface engineering of lentiviral vectors for gene transfer into gene therapy target cells. Curr. Opin. Pharmacol. 2015, 24, 79-85. [CrossRef]

13. Frecha, C.; Szecsi, J.; Cosset, F.-L.; Verhoeyen, E. Strategies for targeting lentiviral vectors. Curr. Gene Ther. 2008, 8, 449-460. [CrossRef]

14. Cronin, J.; Zhang, X.-Y.; Reiser, J. Altering the tropism of lentiviral vectors through pseudotyping. Curr. Gene Ther. 2005, 5, 387-398. [CrossRef]

15. Bischof, D.; Cornetta, K. Flexibility in cell targeting by pseudotyping lentiviral vectors. Methods Mol. Biol. 2010, 614, 53-68. [PubMed]

16. Gutierrez-Guerrero, A.; Cosset, F.-L.; Verhoeyen, E. Lentiviral vector pseudotypes: Precious tools to improve gene modification of hematopoietic cells for research and gene therapy. Viruses 2020, 12, 1016. [CrossRef]

17. Buchholz, C.J.; Friedel, T.; Büning, H. Surface-engineered viral vectors for selective and cell type-specific gene delivery. Trends Biotechnol. 2015, 33, 777-790. [CrossRef] [PubMed]

18. Frank, A.M.; Buchholz, C.J. Surface-engineered lentiviral vectors for selective gene transfer into sub-types of lymphocytes. Mol. Ther. Methods Clin. Dev. 2019, 12, 19-31. [CrossRef] [PubMed]

19. Funke, S.; Maisner, A.; Mühlebach, M.D.; Koehl, U.; Grez, M.; Cattaneo, R.; Cichutek, K.; Buchholz, C.J. Targeted cell entry of lentiviral vectors. Mol. Ther. 2008, 16, 1427-1436. [CrossRef] [PubMed]

20. Ou, W.; Marino, M.P.; Suzuki, A.; Joshi, B.; Husain, S.R.; Maisner, A.; Galanis, E.; Puri, R.K.; Reiser, J. Specific targeting of human interleukin (IL)-13 receptor alpha2-positive cells with lentiviral vectors displaying IL-13. Hum. Gene Ther. Methods 2012, $23,137-147$. [CrossRef]

21. Anliker, B.; Abel, T.; Kneissl, S.; Hlavaty, J.; Caputi, A.; Brynza, J.; Schneider, I.C.; Münch, R.C.; Petznek, H.; Kontermann, R.E.; et al. Specific gene transfer to neurons, endothelial cells and hematopoietic progenitors with lentiviral vectors. Nat. Methods 2010, 7, 929-935. [CrossRef] [PubMed]

22. Münch, R.C.; Mühlebach, M.D.; Schaser, T.; Kneissl, S.; Jost, C.; Plückthun, A.; Cichutek, K.; Buchholz, C.J. DARPins: An efficient targeting domain for lentiviral vectors. Mol. Ther. 2011, 19, 686-693. [CrossRef] [PubMed]

23. Yu, J.H.; Schaffer, D.V. Selection of novel vesicular stomatitis virus glycoprotein variants from a peptide insertion library for enhanced purification of retroviral and lentiviral vectors. J. Virol. 2006, 80, 3285-3292. [CrossRef]

24. Nesbeth, D.; Williams, S.L.; Chan, L.; Brain, T.; Slater, N.K.; Farzaneh, F.; Darling, D. Metabolic biotinylation of lentiviral pseudotypes for scalable paramagnetic microparticle-dependent manipulation. Mol. Ther. 2006, 13, 814-822. [CrossRef] [PubMed]

25. Annoni, A.; Gregori, S.; Naldini, L.; Cantore, A. Modulation of immune responses in lentiviral vector-mediated gene transfer. Cell Immunol. 2019, 342, 103802. [CrossRef]

26. DePolo, N.J.; Reed, J.D.; Sheridan, P.L.; Townsend, K.; Sauter, S.L.; Jolly, D.J.; Dubensky, T.W. VSV-G pseudotyped lentiviral vector particles produced in human cells are inactivated by human serum. Mol. Ther. 2000, 2, 218-222. [CrossRef] [PubMed]

27. Munis, A.M.; Mattiuzzo, G.; Bentley, E.M.; Collins, M.K.; Eyles, J.E.; Takeuchi, Y. Use of heterologous vesiculovirus G proteins circumvents the humoral anti-envelope immunity in lentivector-based In Vivo gene delivery. Mol. Ther. Nucleic Acids 2019, 17, 126-137. [CrossRef] 
28. Schauber-Plewa, C.; Simmons, A.; Tuerk, M.J.; Pacheco, C.D.; Veres, G. Complement regulatory proteins are incorporated into lentiviral vectors and protect particles against complement inactivation. Gene Ther. 2005, 12, 238-245. [CrossRef]

29. Croyle, M.A.; Callahan, S.M.; Auricchio, A.; Schumer, G.; Linse, K.D.; Wilson, J.M.; Brunner, L.J.; Kobinger, G.P. PEGylation of a vesicular stomatitis virus $G$ pseudotyped lentivirus vector prevents inactivation in serum. J. Virol. 2004, 78, 912-921. [CrossRef]

30. Liang, M.; Yan, M.; Lu, Y.; Chen, I.S. Retargeting vesicular stomatitis virus glycoprotein pseudotyped lentiviral vectors with enhanced stability by In Situ synthesized polymer shell. Hum. Gene Ther. Methods 2013, 24, 11-18. [CrossRef] [PubMed]

31. Keryer-Bibens, C.; Barreau, C.; Osborne, H.B. Tethering of proteins to RNAs by bacteriophage proteins. Biol. Cell 2008, 100, 125-138. [CrossRef]

32. Baron-Benhamou, J.; Gehring, N.H.; Kulozik, A.E.; Hentze, M.W. Using the lambdaN peptide to tether proteins to RNAs. Methods Mol. Biol. 2004, 257, 135-154. [PubMed]

33. Di Tomasso, G.; Lampron, P.; Dagenais, P.; Omichinski, J.G.; Legault, P. The ARiBo tag: A reliable tool for affinity purification of RNAs under native conditions. Nucleic Acids Res. 2011, 39, e18. [CrossRef] [PubMed]

34. Austin, R.J.; Xia, T.; Ren, J.; Takahashi, T.T.; Roberts, R.W. Differential modes of recognition in N peptide-box B complexes. Biochemistry 2003, 42, 14957-14967. [CrossRef] [PubMed]

35. Austin, R.J.; Xia, T.; Ren, J.; Takahashi, T.T.; Roberts, R.W. Designed arginine-rich RNA-binding peptides with picomolar affinity. J. Am. Chem. Soc. 2002, 124, 10966-10967. [CrossRef]

36. Nakamura, T.; Peng, K.-W.; Vongpunsawad, S.; Harvey, M.; Mizuguchi, H.; Hayakawa, T.; Cattaneo, R.; Russell, S.J. Antibodytargeted cell fusion. Nat. Biotechnol. 2004, 22, 331-336. [CrossRef]

37. Zadeh, J.N.; Steenberg, C.D.; Bois, J.; Wolfe, B.R.; Pierce, M.B.; Khan, A.R.; Dirks, R.M.; Pierce, N.A. Nupack: Analysis and design of nucleic acid systems. J. Comput. Chem. 2010, 32, 170-173. [CrossRef]

38. Li, N.; Ebright, J.N.; Stovall, G.M.; Chen, X.; Nguyen, H.H.; Singh, A.; Syrett, A.; Ellington, A.D. Technical and biological issues relevant to cell typing with aptamers. J. Proteome Res. 2009, 8, 2438-2448. [CrossRef]

39. Li, N.; Larson, T.; Nguyen, H.H.; Sokolov, K.V.; Ellington, A.D. Directed evolution of gold nanoparticle delivery to cells. Chem. Commun. 2010, 46, 392-394. [CrossRef]

40. Afonin, K.A.; Viard, M.; Koyfman, A.Y.; Martins, A.N.; Kasprzak, W.K.; Panigaj, M.; Desai, R.; Santhanam, A.; Grabow, W.W.; Jaeger, L.; et al. Multifunctional RNA nanoparticles. Nano Lett. 2014, 14, 5662-5671. [CrossRef]

41. Giard, D.J.; Aaronson, S.A.; Todaro, G.J.; Arnstein, P.; Kersey, J.H.; Dosik, H.; Parks, W.P. In Vitro cultivation of human tumors: Establishment of cell lines derived from a series of solid tumors. J. Natl. Cancer Inst. 1973, 51, 1417-1423. [CrossRef] [PubMed]

42. Tahiri-Alaoui, A.; Frigotto, L.; Manville, N.; Ibrahim, J.; Romby, P.; James, W. High affinity nucleic acid aptamers for streptavidin incorporated into bi-specific capture ligands. Nucleic Acids Res. 2002, 30, e45. [CrossRef] [PubMed]

43. Barth, R.F.; Yang, W.; Adams, D.M.; Rotaru, J.H.; Shukla, S.; Sekido, M.; Tjarks, W.; Fenstermaker, R.A.; Ciesielski, M.; Nawrocky, M.M.; et al. Molecular targeting of the epidermal growth factor receptor for neutron capture therapy of gliomas. Cancer Res. 2002, 62, 3159-3166.

44. Marino, M.P.; Panigaj, M.; Ou, W.; Manirarora, J.; Wei, C.-H.; Reiser, J. A scalable method to concentrate lentiviral vectors pseudotyped with measles virus glycoproteins. Gene Ther. 2015, 22, 280-285. [CrossRef] [PubMed]

45. Takahashi, M. Aptamers targeting cell surface proteins. Biochimie 2018, 145, 63-72. [CrossRef] [PubMed]

46. Cerchia, L.; de Franciscis, V. Targeting cancer cells with nucleic acid aptamers. Trends Biotechnol. 2010, 28, 517-525. [CrossRef]

47. Tan, W.; Wang, H.; Chen, Y.; Zhang, X.; Zhu, H.; Yang, C.; Yang, R.; Liu, C. Molecular aptamers for drug delivery. Trends Biotechnol. 2011, 29, 634-640. [CrossRef]

48. Panigaj, M.; Reiser, J. Aptamer guided delivery of nucleic acid-based nanoparticles. DNA RNA Nanotechnol. 2016, 2, 42. [CrossRef]

49. Baron-Benhamou, J.; Gehring, N.H.; Kulozik, A.E.; Hentze, M.W.; Schoenberg, D.R. Using the $\lambda N$ peptide to tether proteins to RNAs. In mRNA Processing and Metabolism; Schoenberg, D.R., Ed.; Humana Press: Totowa, NJ, USA, 2004; Volume 257, pp. 135-154.

50. Bardwell, V.J.; Wickens, M. Purification of RNA and RNA-protein complexes by an R17 coat protein affinity method. Nucleic Acids Res. 1990, 18, 6587-6594. [CrossRef]

51. Bos, T.J.; Nussbacher, J.K.; Aigner, S.; Yeo, G.W. Tethered function assays as tools to elucidate the molecular roles of RNA-binding proteins. Adv. Exp. Med. Biol. 2016, 907, 61-88. [CrossRef]

52. Zhang, X.Y.; Kutner, R.H.; Bialkowska, A.; Marino, M.P.; Klimstra, W.B.; Reiser, J. Cell-specific targeting of lentiviral vectors mediated by fusion proteins derived from Sindbis virus, vesicular stomatitis virus, or avian sarcoma/leukosis virus. Retrovirology 2010, 7, 1. [CrossRef] [PubMed]

53. Leber, M.F.; Neault, S.; Jirovec, E.; Barkley, R.; Said, A.; Bell, J.C.; Ungerechts, G. Engineering and combining oncolytic measles virus for cancer therapy. Cytokine Growth Factor Rev. 2020, 56, 39-48. [CrossRef] [PubMed]

54. Argaw, T.; Marino, M.P.; Timmons, A.; Eldridge, L.; Takeda, K.; Li, P.; Kwilas, A.; Ou, W.; Reiser, J. In vivo targeting of lentiviral vectors pseudotyped with the Tupaia paramyxovirus H glycoprotein bearing a cell-specific ligand. Mol. Ther. Methods Clin. Dev. 2021, 21, 670-680. [CrossRef]

55. Shirley, J.L.; de Jong, Y.P.; Terhorst, C.; Herzog, R.W. Immune responses to viral gene therapy vectors. Mol. Ther. 2020, 28 , 709-722. [CrossRef] [PubMed]

56. Bruno, J.G. Potential inherent stimulation of the innate immune system by nucleic acid aptamers and possible corrective approaches. Pharmaceuticals 2018, 11, 62. [CrossRef] 
57. Kuroda, H.; Kutner, R.H.; Bazan, N.G.; Reiser, J. Simplified lentivirus vector production in protein-free media using polyethylenimine-mediated transfection. J. Virol. Methods 2009, 157, 113-121. [CrossRef]

58. Zhang, X.-Y.; La Russa, V.F.; Reiser, J. Transduction of bone-marrow-derived mesenchymal stem cells by using lentivirus vectors pseudotyped with modified RD114 envelope glycoproteins. J. Virol. 2004, 78, 1219-1229. [CrossRef]

59. Kutner, R.H.; Zhang, X.Y.; Reiser, J. Production, concentration and titration of pseudotyped HIV-1-based lentiviral vectors. Nat. Protoc. 2009, 4, 495-505. [CrossRef] [PubMed] 